STUDI

FRANCESI
Studi Francesi

Rivista quadrimestrale fondata da Franco Simone

145 (XLIX | I) | 2005

Varia - fasc. I - gennaio-aprile 2005

\title{
Marmontel. Une rhétorique de l'apaisement. Études réunies et présentées par Jacques Wagner
}

\section{Regina Bochenek-Franzczakowa}

\section{(2) OpenEdition}

1 Journals

\section{Édition électronique}

URL : http://journals.openedition.org/studifrancesi/36223

DOI : 10.4000/studifrancesi.36223

ISSN : 2427-5856

Éditeur

Rosenberg \& Sellier

\section{Édition imprimée}

Date de publication : 1 juillet 2005

Pagination : 170-171

ISSN : 0039-2944

\section{Référence électronique}

Regina Bochenek-Franzczakowa, "Marmontel. Une rhétorique de l'apaisement. Études réunies et présentées par Jacques Wagner », Studi Francesi [En ligne], 145 (XLIX | I) | 2005, mis en ligne le 30 novembre 2015, consulté le 18 avril 2021. URL : http://journals.openedition.org/studifrancesi/36223 ; DOI : https://doi.org/10.4000/studifrancesi.36223 


\title{
Marmontel. Une rhétorique de l'apaisement. Études réunies et présentées par Jacques Wagner
}

\author{
Regina Bochenek-Franzczakowa
}

\section{RÉFÉRENCE}

Marmontel. Une rhétorique de l'apaisement. Études réunies et présentées par JACQUES WAGNER, Louvain-Paris, Éditions Peeters, 2003, p. 228.

Marmontel est un auteur des Lumières que l'on ne cesse de découvrir, ce dont le présent volume est une preuve spectaculaire. Les études réunies, présentées et commentées de manière éclairante par Jacques WAGNER (Marmontel ou l'horreur $d u$ conflit, p. 5-16), nous font parcourir l'ensemble de l'œuvre marmontélienne considérée par le biais de la «rhétorique de l'apaisement», c'est-à-dire, le «souci de l'unité» et l'esprit de conciliation qui caractérisent le tempérament créateur de cet écrivain. L'ouvrage est composé de deux parties, elles-memes divisées en unités autonomes. La partie I («Les écrits doctrinaux») groupe des études autour de trois unités: l'esthétique, le pédagogique et la poétique. La première apporte des considérations sur les textes théoriques de Marmontel traitant de la littérature et des arts. Jan HERMAN («De quelle utilité peut être le mensonge?» ou le dilemme du roman, p. 21-34) se demande si l'écrivain était pris, lui aussi, dans le «dilemme du roman». L'analyse du problème de la «vraisemblance» dans deux textes théoriques de Marmontel, permet de comprendre l'hostilité, en apparence paradoxale, de l'auteur des contes moraux envers le roman. Marc BUFFAT (L'âme contre les sens ou l'esthétique spiritualiste des «Eléments de littérature» $\mathrm{p}$. 35-49), en examinant les idées de Marmontel sur les arts, y trouve une conception hiérarchisée, fondée sur la dualité: corps/âme; celle-ci est dépourvue pourtant de sens spirituel et religieux. La partie consacrée au "pédagogique» contient deux études. Michael CARDY (Regards sur le «Cours d'études pour ses fils», p. 53-64) présente un texte peu 
connu de Marmontel, datant de la Révolution, le Cours d'études pour ses fils où l'écrivain vieillissant et aigri par les expériences tente un retour aux croyances simples de sa jeunesse, dans l'espoir de «sauver du naufrage quelques restes qu'il estimait précieux» (p. 64). Anné QUENNEDEY (Marmontel orateur. Discours politiques de l'an V, p. 65-77) examine les quelques discours de Marmontel prononcés au Conseil des Anciens en septembre 1797. L'étude de l'éloquence de Marmontel montre «l'omniprésence de l'analyse morale dans les textes dont l'enjeu est politique», dessinant «la figure d'un sage vieillard, ennemi des conflits d'opinions» (p. 75). La «poétique» est représentée par l'étude de Jacques-Philip AINT-GERAND, Le Javelot de Marmontel au XIXe siècle, p. 81-102). À travers la postérité des écrits de l'Encyclopédie et de l'Encyclopédie méthodique, l'A. cherche à définir ce que le XIX ${ }^{e}$ siècle devait aux conceptions de Marmoel sur l'utilisation de la langue française, l'écriture et le style. Dans la partie II du recueil («Les œuvres narratives»), les études sont regroupées selon les genres pratiqués par Marmontel. Jean-Noël PASCAL se penche sur l'œuvre peu connue de l'écrivain, le théâtre. La question posée dans le titre de l'étude (Les tragédies de Marmontel: demi-échec ou demi-réussite? p. 107-134) mène à une réponse prévisible: malgré une contribution considérable à l'histoire de la tragédie au $18^{\mathrm{e}}$ siècle, le théâtre marmontélien ne diffère pas de la tragédie de l'époque, qui était celle des épigones. Deux études sont consacrées aux romans de Marmontel. Robert GRANDEROUTE («Bélisaire»: une décence éclatée, p. 137-150) rappelle la querelle suscitée par le Bélisaire, en examinant la Censure de la Faculté de Théologie de Paris, un des ouvrages qui symbolisait la résistance religieuse de l'époque aux idées nouvelles dont le roman de Marmontel était une expression emblématique et controversable. Paul PELCKMANS («Chargez-le donc seul des méfaits dont son imposture est la cause...». Fanatisme et domination coloniale dans "Les Incas», p. 151-161) se demande pourquoi dans les Incas, le personnage de Pizarre est constitué, contre toute vraisemblance, en homme des Lumières. Aux yeux de l'A., Pizarre a pu séduire Marmontel car il incarnait la version énergique du programme moderne. Il a le beau rôle: celui de l'ambitieux énergique qui ne recule devant rien pour atteindre les buts qu'il s'est fixés. Le genre le plus connu de Marmontel, le conte moral, est l'objet de deux études. Katherine ASTBURY (Marmontel, éditeur du "Mercure de France» et ses "Contes moraux», p. 165-174) observe comment le travail de Marmontel au Mercure de France a contribué aux Contes moraux. L'analyse atteste que l'écrivain était «un baromètre de son époque» (p. 174) et que le temps passé au Mercure de France a changé radicalement son concept de conte moral. Khaled BEN SIDRA (Moralisme et immoralité dans les «Contes moraux» de Marmontel, p. 175-191) propose une lecture de quelques contes marmontéliens à caractère libertin, en montrant que toute tentative de classer ces contes d'une manière rigoureuse est ici malaisée et arbitraire. La dernière étude de cette deuxième partie du recueil concerne l'écriture mémorialiste de l'écrivain. Hélène cusSAC (Réécriture de la retraite dans les "Contes» et les «Mémoires» de Marmontel, p. 195-213) aborde cette question par le biais du motif de la «retraite» que l'écrivain réécrit dans ses contes et ses Mémoires selon son tempérament, se situant dans le sillage plutôt horatien que rousseauiste. Dans la conclusion ( $D u$ bon usage des morts et des vivants, p. 217-222), Jacques WAGNER insiste sur le tempérament conciliateur de Marmontel qui le poussait à donner à l'écriture «une mission de régulation» et d'écarter les conflits, atténuer les antagonismes par une discipline permanente (p. 217-218). L'A. rappelle enfm le fait que le «néoplatonisme marmontélien» a fait autorité tout au long du $19^{\mathrm{e}}$ siècle, nourrissant en profondeur les entreprises esthétiques et politiques conservatrices, entre autres, à travers l'éducation étatisée. Les études réunies dans ce volume dessinent une image très riche et à la fois 
cohérente de l'œuvre de Marmontel, dégageant les tendances principales à travers la variété des genres pratiqués par cet écrivain dont la postérité n'a trop longtemps retenu que les «contes moraux». 